\title{
Rebound Bursts in GABAergic Neurons of the Thalamic Reticular Nucleus in Postnatal Mice
}

\author{
X. WANG ${ }^{1^{*}}$, G. YU ${ }^{1 *}$, X. HOU ${ }^{1}$, J. ZHOU ${ }^{1}$, B. YANG ${ }^{2}$, L. ZHANG \\ * These authors contributed equally to the work and should be considered as co-first authors. \\ ${ }^{1}$ Department of Neurology, First Clinical College, Harbin Medical University, Harbin, \\ Heilongjiang, China, ${ }^{2}$ Institute of Pharmacology, Harbin Medical University, Harbin, Heilongjiang, \\ China
}

Received May 22, 2008

Accepted February 19, 2009

On-line June 19, 2009

\section{Summary}

Whole cell patch-clamp recordings from GABAergic cells of thalamic reticular nucleus (RTN) in thalamocortical slices made from postnatal day 6 (P6) to 10 (P10) were used to investigate the pattern of rebound bursts (RBs) triggered by an injection of hyperpolarizing current into RTN cells. The number of RBs in the RTN and the overlying $\mathrm{Na}^{+} / \mathrm{K}^{+}$spikes changed in an agedependent manner. The generation of RBs depended largely on the amplitude of the after-hyperpolarizations (AHPs). RB patterns in response to hyperpolarizing current injection into relay cells were markedly different from RB patterns in RTN cells with an after-depolarization. $G_{A B A_{A}}$ receptor antagonist bicuculline methiodide (BMI) changed burst firing patterns, increasing the duration of RB and decreasing the amplitude of AHP in RTN cells. Furthermore, local puffs of NMDA in the presence of BMI induced RBs. $\mathrm{K}^{+}$channel blocker 4-aminopyridine partially mimicked the effect of BMI on AHPs. The shapes of RBs were altered by a selective CaMKII inhibitor KN-62, but not by an inactive analog $\mathrm{KN}-04$.

\section{Key words}

Thalamic reticular nucleus $\bullet$ Rebound burst $\bullet$ Postnatal mice • After-hyperpolarization

\section{Corresponding author}

L. Zhang, Department of Neurology, First Clinical College, Harbin Medical University, Youzheng Street No. 23, Nangang District, Harbin, Heilongjiang Province, 150001, China. Fax: 86-451-53661120. E-mail: happywangxun@yahoo.com.cn; zfx001@yahoo.com

\section{Introduction}

Thalamic burst firings have long been implicated in the pathogenesis of childhood absence epilepsy (Shin 2006). Thalamic reticular nucleus (RTN) cells and intraRTN inhibition may constitute particularly efficient therapeutic targets (Sohal and Huguenard 2003). RTN, composed entirely of GABAergic neurons, is the main inhibitory component of the thalamocortical network (Shu and McCormick 2002, Zhang and Jones 2004). RTN neurons in vivo exhibit at least two major response patterns: burst firing and tonic firing, both occurring in after-hyperpolarizations (AHPs). The AHP - a major determinant of cell excitability - plays a crucial role in priming and sustaining the burst (Fernández de Sevilla et al. 2006). Burst firing also relays information as efficiently as tonic firing, but its consequences for information processing are markedly different (Llinás and Steriade 2006).

The firing pattern of RTN neurons depends on the activation of both excitatory and inhibitory inputs. In addition to the excitatory and inhibitory neurotransmitters - glutamate (Alexander and Godwin 2006) and $\gamma$-aminobutyric acid (GABA) (Ben-Ari et al. 2007), ion channels such as T-type $\mathrm{Ca}^{2+}$ channels (Shin 2006) and $\mathrm{K}^{+}$channels (Debarbieux et al. 1998) are involved in modulating thalamocortical circuits and burst firing, yet their actions on postnatal RTN are unknown.

Developmental changes in the nervous system affect the clinical expression of age-dependent 
genetically-determined generalized epilepsy syndromes (Sanchez and Jensen 2001). Some studies have suggested that the thalamic circuit and properties of thalamic neurons underlying spindle waves in EEG are not fully functional in newborns and develop over a relatively long postnatal period (Mareš et al. 1982, Domich et al. 1987). However, the status of rebound bursts (RBs) - induced by hyperpolarizing stimuli during the postnatal period - is unknown, although some aspects of burst discharge have been observed in RTN neurons of immature animals (Warren and Jones 1997). RTN neurons in mice have typical morphology between postnatal days 6 (P6) and 11 (P11). During this period the axons from RTN cells have already entered the underlying ventral posterior (VP) nucleus and terminated in a compact ramification implying restriction to a VP barreloid. Furthermore, firing properties indicate that RB discharges are ready to be evoked (Warren and Jones 1997, Zhang and Jones 2004). Therefore, using the whole cell patch-clamp technique, we recorded the RBs triggered by an injection of hyperpolarizing current into RTN cells and observed burst and tonic discharge patterns in RTN slices of young mice from P6 to P10. We also tested the effects of some ion channel drugs on firing patterns of RTN neurons.

\section{Materials and Methods}

\section{Slice preparation}

All procedures involving animals followed the guidelines and protocols approved by the Care and Use of Animals Committee of Harbin Medical University. Brain slices were prepared according to our previous study (Zhang and Jones 2004, Zhang and Warren 2008). P6 to P10 ICR mice (Harlan Sprague-Dawley) were anesthetized with ether and decapitated. The brain was quickly removed and put into chilled artificial cerebrospinal fluid (ACSF), in which $126 \mathrm{mM} \mathrm{NaCl}$ had been replaced by sucrose at equivalent osmolarity, and contained (in mM) 252 sucrose, $3 \mathrm{KCl}, 1.25 \mathrm{NaH}_{2} \mathrm{PO}_{4}$, $1.3 \mathrm{MgSO}_{4}, 2.5 \mathrm{CaCl}_{2}, 26 \mathrm{NaHCO}_{3}$, and 10 dextrose. The solution had a pH of 7.4 when bubbled with $95 \% \mathrm{O}_{2}-5 \%$ $\mathrm{CO}_{2}$, and an osmolarity of 300-315 mosmol/l. Slices (400- $\mu \mathrm{m}$ thick) containing the somatosensory cortex, RTN, and ventrobasal complex (VB) were cut at an angle that preserved corticothalamic and thalamocortical connectivity (Agmon and Connors 1991). The slices were cut on a vibratome (NVSLM1, WPI Inc., Sarasota, FL) while immersed in chilled ACSF and were then transferred to a submerged-type recording chamber continuously superfused with ACSF aerated with $95 \%$ $\mathrm{O}_{2}-5 \% \mathrm{CO}_{2}$ at a rate of $1.5 \mathrm{ml} / \mathrm{min}$. The slices were allowed to recover for at least one hour before recording. All experiments were performed at room temperature $\left(20-22{ }^{\circ} \mathrm{C}\right)$.

\section{Recording and data analysis}

The RTN was visualized with Nikon FN1 upright research microscope (Nikon, Tokyo, Japan). Whole cell patch-clamp recordings were performed using an Axopatch 200B amplifier (Axon Instruments, Foster City, CA). Recording pipettes were pulled from borosilicate glass on a Narishige PP-830 two-stage puller. In the experiments, pipettes had a resistance of 3-5 $\mathrm{M} \Omega$ when filled with internal solutions containing (in $\mathrm{mM}$ ) 130 potassium gluconate, $10 \mathrm{KCl}, 2 \mathrm{MgCl}_{2}, 0.1 \mathrm{CaCl}_{2}$, 1.1 EGTA, 10 HEPES, $2 \mathrm{~K}_{2}$-ATP, and 0.5 GTP. The $\mathrm{pH}$ was adjusted to 7.3 with $\mathrm{KOH}(8 \mathrm{~N})$. Series resistance during recordings was regularly 5-25 $\mathrm{M} \Omega$. Data were low-pass-filtered at $2-10 \mathrm{kHz}$ and digitized at $1-10 \mathrm{kHz}$ via a CED 1401 plus interface (Cambridge Electronic Design, Cambridge, UK) with a pentium-based computer (Lenovo) that stored the data and provided on-line display of responses and off-line data analysis.

RBs were elicited by injecting a $-200 \mathrm{pA}$ current (duration $1000 \mathrm{~ms}$ ) through the recording electrode during current-clamp mode. The number of RBs and the maximal number of spikes overlying them were calculated over a period of $10 \mathrm{~s}$ for every cell tested. Duration, amplitude, and area of the initial RB AHP were estimated (Fig. 1C2). Amplitude of the AHP was measured from the rest membrane potential (RMP) to its peak amplitude, whereas the duration was calculated from the point at which the downstroke of the action potential crossed the RMP to return to the baseline potential. The integrated area of AHP was calculated from the potential offset for the entire duration of AHP. All data were acquired and analyzed using Signal 3.06 (Cambridge Electronic Design, UK) software. Plots were made using Origin 8.0 (Microcal Software, Northampton, MA) and SigmaPlot 10.0 (Systat Software, Inc.). Statistical analysis was performed using SigmaStat software (Systat Software, Inc.). Parametric tests were used if the data met the assumptions of the appropriate test, otherwise nonparametric tests were used. Data are presented as means \pm S.E.M. and $p<0.05$ was required for statistical significance. 
A

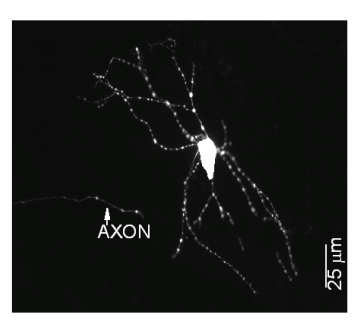

C1

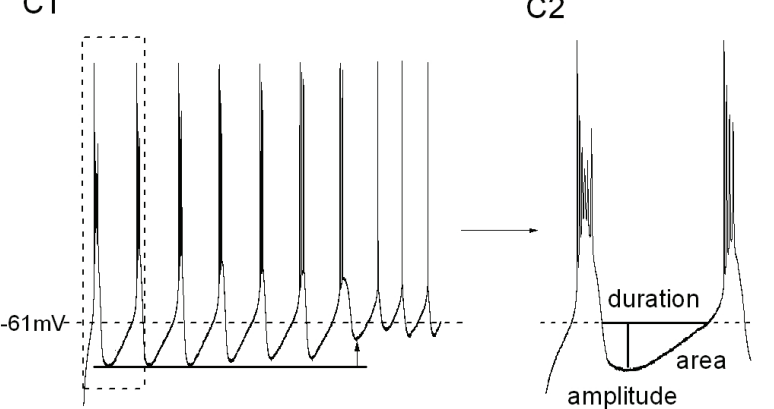

B

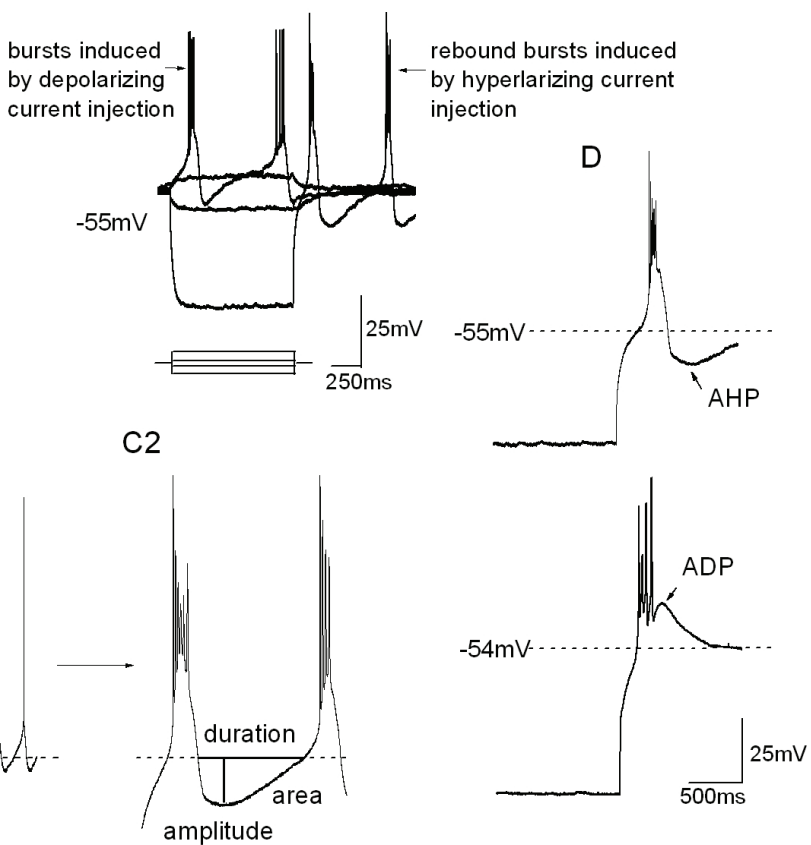

Fig. 1. (A) Image of a section of a biocytin-labeled RTN neuron at P6. The cell has radially symmetrical thin and beaded dendrites. Arrow shows the axon of this neuron. (B) Firing characteristics of a RTN neuron at P10. -200 pA and +200 pA current injection induced RBs and bursts, respectively. Subthreshold current of $-50 \mathrm{pA}$ and $+50 \mathrm{pA}$ did not evoke any burst or tonic firing. (C1) RBs of a RTN neuron at P8. RBs shifted to tonic discharge when the amplitude of AHP decreased markedly (arrow) compared with the initial one. (C2) Two magnified RBs from highlighted region illustrate the measurement of duration, amplitude and area of AHP. (D) Respective RB firing characteristic of RTN (up) and VB (bottom) neurons. Arrows show AHP (up) and ADP (bottom).

\section{Cell morphology}

Biocytin $(0.5 \%)$ was present in the internal solution of the recording pipette during all recordings. Slices were fixed in $4 \%$ paraformaldehyde in $0.1 \mathrm{M}$ phosphate buffer and resectioned (10 $\mu \mathrm{m}$ thick) when needed. Staining was done by avidin-biotin-peroxidase complex (ABC kit PK-4000) method and reacted with 3,3'-diaminobenzidine-4HCl to visualize injected cells. Slices were then viewed under the microscope (Fig. 1A1).

\section{Drug application}

BMI (bicuculline methiodide) $(10 \mu \mathrm{M})$ and 4-AP (4-aminopyridine) $(1 \mathrm{mM})$ were applied in bath solution, respectively. Puffs of NMDA (N-methyl-D-aspartate) $(100 \mu \mathrm{M})$ were applied locally to the RTN through a glass micropipette connected to Picospritzer III (General Valve, Parker Hannifin Corporation, Rohnert Park, CA). KN-62 (1-[N,O-bis(5-osoquinolinesulfonyl)-N-methyl-L-tyrosyl]4-phenylpiperazine) $(5 \mu \mathrm{M})$ or $\mathrm{KN}-04$ ([N-(1-1[P-(5isoquinolinsulfonyl)benzyl]-2-(4-phenyl-piperazinyl)ethyl) -5-isoquinolinsulfonamide) $(10 \mu \mathrm{M})$ was given in the pipette solution. All drugs and chemicals were obtained from Sigma-Aldrich (St. Louis, MO, USA).

\section{Results}

Firing characteristics of RTN cells in mice from P6 to P10

Tonic and burst firing were observed in RTN cells in our experiment. RTN cells usually exhibited a spontaneous tonic firing in current patch-clamp recordings. Once a hyperpolarizing current pulse $(-200 \mathrm{pA})$ was applied, RTN cells $(\mathrm{n}=33)$ would produce repetitive $\mathrm{RB}$ consisting of the transient discharge of multiple $\mathrm{Na}^{+} / \mathrm{K}^{+}$action potentials followed by a slow and large AHP. Furthermore, application of a depolarizing current elicited burst discharges similar to RBs evoked by hyperpolarizing current in RTN neurons (Fig. 1B). The pattern of persistent RBs was regular and stereotypic. Once initiated, the repetitive rebound bursts were sustained by AHP unless the amplitude of the AHP was not sufficient to induce another RB. However, RBs shifted to tonic firing when there was a sudden reduction in the amplitude of AHP (Fig. C1). Thus, AHP functioned as a major determinant of the subsequent firing mode in RTN cells. During recordings, most neurons in the rostral part $(88 \%, 29 / 33)$, in contrast to cells in the caudal part, fired more than one RB. We also found that relay cells of the VB (unlike RTN cells) fired exclusively single RBs with an after-depolarization (ADP), in response to a hyperpolarizing current pulse (Fig. 1D).

On the basis of a limited number of samples, we concluded that RBs in the postnatal period tended to last longer with age (Fig. 2A). Younger cells (P6 and P7) usually fired 1-3 RBs; some cells at P8 fired 6-9 RBs, and several older postnatal cells fired even more. Sometimes RBs were prolonged in neurons at P9 and P10. 

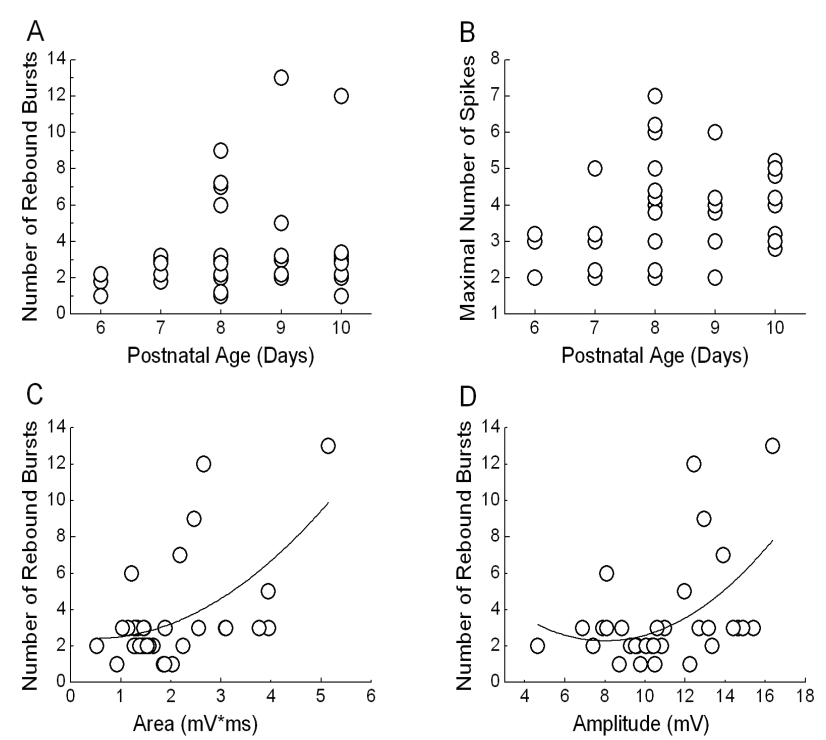

Fig. 2. (A) and (B) Plots of the number of RBs and maximal number of $\mathrm{Na}^{+} / \mathrm{K}^{+}$spikes over a period of $10 \mathrm{sec}$ in RTN cells from P6 to P10. Each circle represents the value from a single neuron. (C) and (D) Relations between the number of RBs and AHP. Significant correlations were found between the number of RBs and area $\left(C, r^{2}=0.25381, p=0.0047\right)$ as well as amplitude $\left(D, r^{2}=0.20069, p=0.01319\right)$ of the initial AHP. The values were best fit by a second-order polynomial regression.

Furthermore, as mentioned before, the number of RBs appeared to be significantly correlated with the area $\left(\mathrm{r}^{2}=0.25381, \mathrm{p}<0.01\right)$ and amplitude $\left(\mathrm{r}^{2}=0.20069\right.$, $\mathrm{p}<0.05$ ) of the initial AHP (Fig. 2C and D), although this area and amplitude did not change markedly with age (i.e. postnatal days). In addition, the maximal number of $\mathrm{Na}^{+} / \mathrm{K}^{+}$spikes associated with each $\mathrm{RB}$ (2-3 at P6) also increased with age and reached 7 at P8 (Fig. 2B). The number of RBs and maximal number of $\mathrm{Na}^{+} / \mathrm{K}^{+}$spikes per burst increased from $\mathrm{P} 6$ to $\mathrm{P} 8$, respectively, on average $140 \%$ and $60 \%$.

\section{BMI altered the number of rebound bursts and inhibited AHP}

RTN neurons are GABAergic and synaptically interconnected, and thus the effects of removing intraRTN inhibition on RB discharges were examined. When $\mathrm{GABA}_{\mathrm{A}}$ receptor antagonist BMI $(10 \mu \mathrm{M})$ was added to the perfusing medium, the most striking effect $(n=6)$ was a two- to three-fold increase in the number of $\mathrm{Na}^{+} / \mathrm{K}^{+}$ action potentials per $\mathrm{RB}$ and the increase in $\mathrm{RB}$ duration (Fig. 3A). Furthermore, the amplitude of AHPs decreased significantly as compared with controls and even vanished with time. Thus, BMI favored the production of RBs and inhibited AHPs, indicating their dependence on a $\mathrm{GABA}_{\mathrm{A}}$ receptor-based mechanism.
A

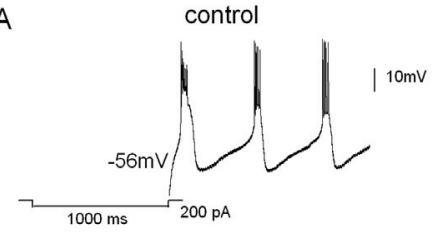

B1

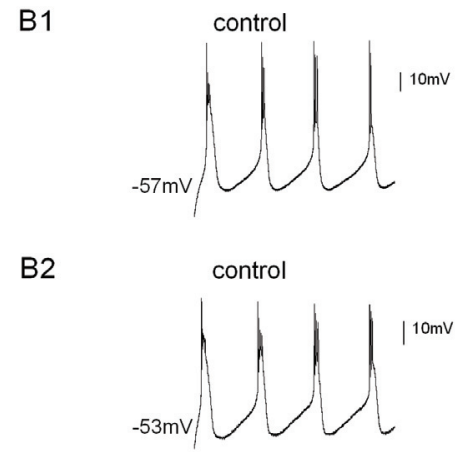

B2
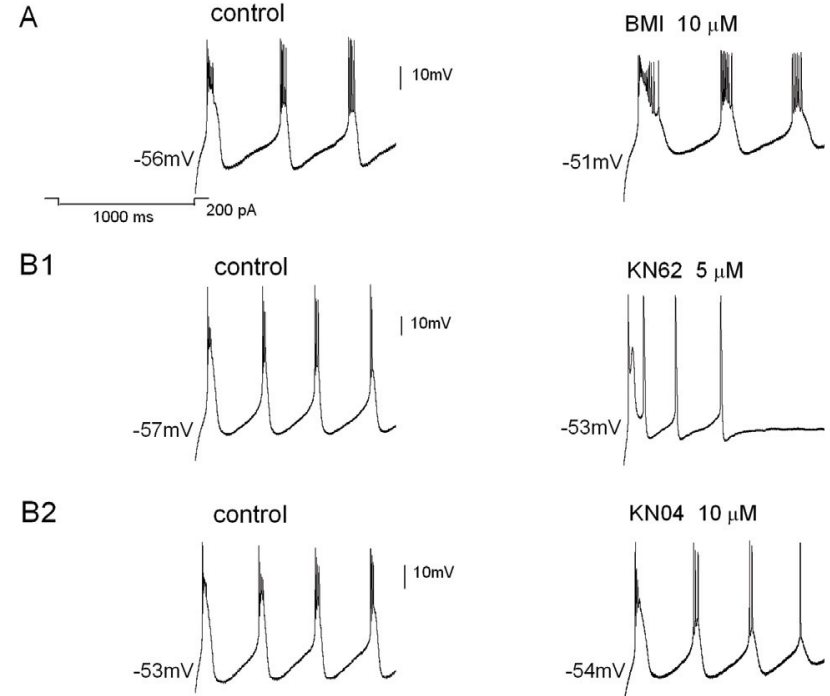

C

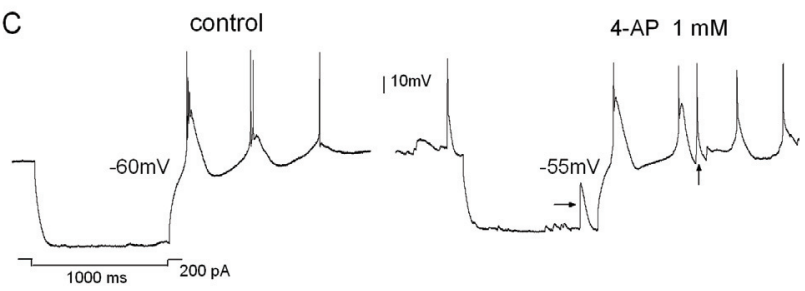

Fig. 3. (A) BMI $(10 \mu \mathrm{M})$ changed the burst firing pattern (i.e. increased the duration of RBs and decreased amplitude of AHPs) in an RTN cell at P10. (B1) KN-62 altered RBs of an RTN cell at P6. (B2) KN-04 had no effect on RBs of a cell at P8. (C) Effect of 4-AP on RBs of a cell at P6. Arrow shows irregular seizure-like spikes.

\section{4-AP abolished AHPs of both rebound bursts and tonic} spikes

Debarbieux et al. (1998) found that the effect of $\mathrm{BMI}$ on bursts was due to direct $\mathrm{K}^{+}$channel blocking. We therefore tested the effects of 4-AP, a $\mathrm{K}^{+}$channel blocker on RBs. When added to the bath solution, 4-AP (1 mM) $(n=6)$ altered firing pattern of RTN cells (i.e., decreased amplitude or area of the AHPs of both tonic and RB discharge with time) (Fig. 3D), mimicking the effect of BMI on burst pattern to some extent. The most distinct effect of 4-AP was increased membrane excitability resulting in many irregular spikes that were neither typical tonic nor burst discharges but looked like epileptiform spikes (Fig. 3D arrow). RBs with such spikes were abolished and tonic spikes were also abolished by prolonged repolarization.

\section{KN-62 inhibited rebound bursts}

$\mathrm{Ca}^{2+} /$ calmodulin-dependent protein kinase II (CaMKII) has recently been found to stimulate T-type $\mathrm{Ca}^{2+}$ channels (Perez-Reyes 2003), which have been demonstrated to play a pivotal role in burst generation in 


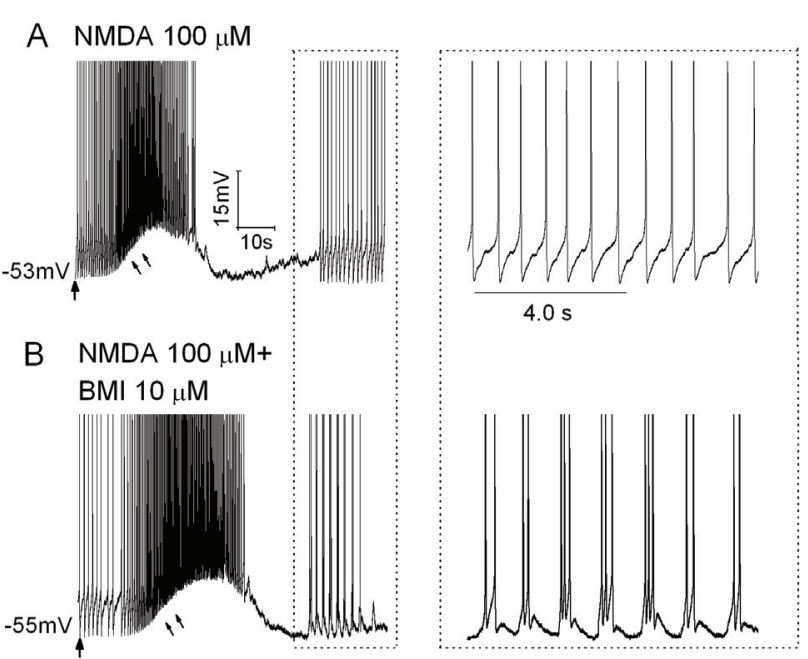

Fig. 4. (A) Effect of local puffs of NMDA $(100 \mu \mathrm{M})$ and (B) perfused with BMI $(10 \mu \mathrm{M})$ following local puffs of NMDA. Double arrow shows depolarized membrane potential. Magnified trace (right) shows the induced brief train of tonic spikes following the membrane depolarization in (A) and burst firing in (B). The action potentials are truncated.

thalamus. We examined the influence of a selective CaMKII inhibitor KN-62 $(5 \mu \mathrm{M})$ on RBs. Soon after recording with $\mathrm{KN}-62(\mathrm{n}=5)$ in the pipette solution, the pattern changed to repetitive single spike firing of progressively increasing frequency during the second $\mathrm{RB}$ (Fig. 3B1). The inter-spike interval and duration of spike firing also increased with time. $\mathrm{Na}^{+} / \mathrm{K}^{+}$spikes on the first $\mathrm{RB}$ diminished rapidly and continued into a relatively flat downstroke followed by a train of tonic discharges. Moreover, the RB AHP decreased abruptly and finally disappeared, mirroring early changes in $\mathrm{Na}^{+} / \mathrm{K}^{+}$spikes. However, the addition of KN-04 (an inactive analogue) to the recording pipette did not block $\mathrm{RBs}$ and AHP (Fig. 3B2), indicating that CaMKII-mediated inhibition could contribute to regulation of RBs.

\section{BMI induced bursts following application of local puffs of NMDA}

The glutamatergic corticothalamic projection that arises from cells of layers V and VI of the cerebral cortex exerts its effects on RTN neurons. Thus, ionotropic glutamate receptor agonist was tested in the present study. Local puffs of NMDA $(100 \mu \mathrm{M})$ increased the frequency of tonic firing while depolarizing the membrane transiently (Fig. 4A double arrow). Interestingly, it induced a brief discharge of repetitive tonic spikes with sharp fast AHPs $(n=5)$ (Fig. 4A) following the depolarization. With BMI $(10 \mu \mathrm{M})$ in the bath, the most prominent effect of local puffs of NMDA was the clustering of evoked spikes into rhythmic burst firing without AHP (Fig. 4B).

\section{Discussion}

Changes in rebound bursts and AHPs during postnatal development

The generation of RBs in our experiment required both the hyperpolarization of the cell with intracellular current injection as well as the occurrence of AHPs. The number of RBs and the number of overlying $\mathrm{Na}^{+} / \mathrm{K}^{+}$spikes were the main changes. Ion channels determine discharge activity, thus developmental changes in ion channel expression lead to the maturation of firing properties. In RTN, the density of $\mathrm{GABA}_{\mathrm{A}}$ receptors in the membrane increased significantly with postnatal development (Gibbs et al. 1996). GABA-labeled synaptic terminals, that are morphologically immature in neonatal animals, become numerous and morphologically mature only after the end of the second postnatal week (De Biasi et al. 1997), which suggest that channel density in young cells was too low to provide sufficient discharge storage to sustain more RBs. In addition, cell membrane surface area and subcellular distribution of channel isoforms may also contribute to the increase in firing properties and firing style of RBs. In comparison with the postnatal RTN neurons, adult RTN cells have spontaneous bursts or synaptically evoked bursts of four to eight spikes with a clear accelerando-decelerando pattern (Contreras et al. 1993, Hartings et al. 2003). These changes in action potential generation are mainly due to the increase in density of $\mathrm{Na}^{+}$and $\mathrm{K}^{+}$channels. Thus the threshold for activation of $\mathrm{Na}^{+}$spikes is likely to decrease (Ramoa and McCormick 1994). The changes in interspike interval may be due to properties of current underlying the lowthreshold spike (Huguenard and Prince 1992). Spike-andwave rhythm is age-dependent and the postnatal development of spindle waves is associated with an increase in the ability of neurons to generate high frequency bursts of action potentials (Mareš et al. 1982, McCormick et al. 1995). Increased RBs are then able to enhance intra-nuclear inhibition, activating downstream $\mathrm{GABA}_{\mathrm{B}}$ receptors, modulating firing activity in thalamic circuits and the thalamocortical network (Sohal and Huguenard 2003), thereby suppressing age-dependent spike-wave discharge, characteristic for generalized absence epilepsy.

The NMDA current was found to reach its peak around P8 (Liu et al. 2004), when cells become 
morphologically adult cells (Warren and Jones 1997), in parallel with the development of RBs in RTN. Such changes in RBs would be important for activities that depend on inhibitory and excitatory connections formed during the normal development of the thalamocortical system.

Difference in RB pattern between RTN and VB cells indicate the important role of AHP in RBs. AHP, reflecting the active ionic conductance after action potentials, plays an essential role in the generation and regulation of burst activity. AHP may change with age. For motoneurons in humans, AHP duration increases gradually with age (Piotrkiewicz et al. 2007), while for brainstem and spinal motoneurons in rats, it decreases with postnatal development (Carrascal et al. 2005). In addition, reduction in slow AHP is a general mechanism underlying learning, with enhancement of AHP being involved in aging-related learning deficit (Wu et al. 2004). In the present study, the AHP did not correlate with age. This may be due to the relatively short period of development that we investigated and/or to the limited number of samples. AHP has been attracting increasing attention for its possible role in both normal brain function and paroxysmal discharges such as epileptic spikes (Llinás and Steriade 2006) and is often a strategic target for modulating neural activity. However, the extent to which AHP underlies the transformation from burst to tonic firing during development is of key importance but remains to be investigated.

\section{$B M I$ and 4-AP both inhibited AHPs and abolished normal firing mode in RTN}

The burst duration, $\mathrm{Na}^{+} / \mathrm{K}^{+}$spikes, and AHPs of hyperpolarizing evoked RBs were sensitive to the application of the $\mathrm{GABA}_{\mathrm{A}}$ receptor antagonist $\mathrm{BMI}$ in our experiment. Similar effects of BMI have previously been seen in the synaptically driven burst response in thalamus and other regions of the brain (Johnson and Seutin 1997, Warren and Jones 1997, Debarbieux et al. 1998). The firing pattern is dependent on both intrinsic properties of neurons and their excitatory and inhibitory synaptic inputs. $\mathrm{GABA}_{\mathrm{A}}$ receptor-based reciprocal inhibition has been demonstrated between RTN neurons. Such effects in the present study indicate that $\mathrm{GABA}_{\mathrm{A}}$ receptor-mediated events have a modulating role in the developing $\mathrm{RB}$ pattern. Particular properties of intra-RTN inhibition restrict intrathalamic activity and regulate thalamic spindle oscillations, thereby preventing the hypersynchronous activity that leads to some forms of epilepsy (Sohal et al. 2000).

However, since the effect of BMI on AHP is not replicated by picrotoxin (Debarbieux et al. 1998), another mechanism of BMI activity has been proposed involving the direct blocking of those $\mathrm{Ca}^{2+}$-dependent $\mathrm{K}^{+}\left(\mathrm{K}_{\mathrm{Ca}}\right)$ channels of small conductance (SK) that are important for excitability control and burst firing in RTN neurons. This hypothesis is consistent with the finding that propofol increases intrinsic excitability and spike firing rate in RTN neurons by blocking SK channels (Ying and Goldstein 2005). The present study found that 4-AP affected RBs by abolishing $\mathrm{Na}^{+} / \mathrm{K}^{+}$spikes and AHPs, indicating that the voltage-gated $\mathrm{K}^{+}$channel is at least partially involved in the effects of BMI, and reflecting that different $\mathrm{K}^{+}$currents are activated in the regulation of AHP. 4-AP has been used to induce epileptiform activity in hippocampal and cortical brain slices and has become a mainstay in epilepsy research (Fueta and Avoli 1992). It also induced epileptiform spikes in the present study.

Local puffs of NMDA changed cell excitability by increasing the tonic firing frequency without inducing any burst. It was in the presence of BMI that burst firing was induced, demonstrating that ionotropic glutamate can stimulate RTN cells to fire but cannot change their firing pattern. We also found that NMDA-dependent burst firing was induced by the metabotropic glutamate receptor agonist trans-ACPD in RTN cells and this effect was enhanced by BMI (in another preparation).

Selective inhibition of CaMKII-mediated signaling may participate in the generation of rebound bursts

T-type $\mathrm{Ca}^{2+}$ channels are thought to transform neuronal output into RB discharge (Molineux et al. 2006). Alterations in thalamic T-type $\mathrm{Ca}^{2+}$ channels are thought to contribute to the pathogenesis of absence seizures (Shin 2006). Both the $\alpha_{1 \mathrm{H}}\left(\mathrm{Ca}_{\mathrm{V}} 3.2\right)$ and $\alpha_{1 \mathrm{I}}$ (Ca 3.3$)$, molecular subtypes of T-type $\mathrm{Ca}^{2+}$ channels are expressed prominently in the RTN, but have different kinetic properties. They are both also involved in burst firing of RTN neurons in the thalamocortical circuitry (Perez-Reyes 2003). T-type channels are also functionally coupled to SK channels, as mentioned before. In substantia nigra dopaminergic neurons, SK channels and T-type channels are coupled and possess almost identical sensitivities to nickel and $\mathrm{Ca}^{2+}$ entering via T-type channels (Wolfart and Roeper 2002). Thus, neuromodulators that reduce the T-type $\mathrm{Ca}^{2+}$ current would also indirectly reduce the SK current under similar circumstances. The ability of CaMKII to stimulate T-type 
currents has been studied recently, and CaMKII inhibitors could block T-type currents measured in whole cell recordings (Perez-Reyes 2003). Welsby et al. (2003) also identified the $\alpha_{1 \mathrm{H}}$ channel as a new substrate for CaMKII. KN-62 (a selective inhibitor of CaMKII) may change the shapes of RBs by blocking T-channels or modulating SK channels and thereby affect firing pattern. These findings in the present study indicated that CaMKII-mediated signaling may participate in the generation of $\mathrm{RB}$ at least during development.

\section{Conflict of Interest}

There is no conflict of interest.

\section{Acknowledgements}

This project was supported by the National Natural Science Foundation of China (30570621), the Technique Project of the Education Department (1055HZ010) and Foundation of the Technology Department (LC05C17) of Heilongjiang Province.

\section{References}

AGMON A, CONNORS BW: Thalamocortical responses of mouse somatosensory (barrel) cortex in vitro. Neuroscience 41: 365-379, 1991.

ALEXANDER GM, GODWIN DW: Metabotropic glutamate receptors as a strategic target for the treatment of epilepsy. Epilepsy Res 71: 1-22, 2006.

BEN-ARI Y, GAIARSA JL, TYZIO R, KHAZIPOV R: GABA: a pioneer transmitter that excites immature neurons and generates primitive oscillations. Physiol Rev 87: 1215-1284, 2007.

CARRASCAL L, NIETO-GONZALEZ JL, CAMERON WE, TORRES B, NUNEZ-ABADES PA: Changes during the postnatal development in physiological and anatomical characteristics of rat motoneurons studied in vitro. Brain Res Brain Res Rev 49: 377-387, 2005.

CONTRERAS D, CURRÓ DOSSI R, STERIADE M: Electrophysiological properties of cat reticular thalamic neurones in vivo. $J$ Physiol Lond 470: 273-294, 1993.

DEBARBIEUX F, BRUNTON J, CHARPAK S: Effect of bicuculline on thalamic activity: a direct blockade of IAHP in reticularis neurons. J Neurophysiol 79: 2911-2918, 1998.

DE BIASI S, AMADEO A, ARCELLI P, FRASSONI C, SPREAFICO R: Postnatal development of GABAimmunoreactive terminals in the reticular and ventrobasal nuclei of the rat thalamus: a light and electron microscopic study. Neuroscience 76: 503-515, 1997.

DOMICH L, OAKSON G, DESCHÊNES M, STERIADE M: Thalamic and cortical spindles during early ontogenesis in kittens. Brain Res 428:140-142, 1987.

FERNÁNDEZ DE SEVILLA D, GARDUÑO J, GALVÁN E, BUÑO W: Calcium-activated afterhyperpolarizations regulate synchronization and timing of epileptiform bursts in hippocampal CA3 pyramidal neurons. J Neurophysiol 96: 3028-3041, 2006.

FUETA Y, AVOLI M: Effects of antiepileptic drugs on 4-aminopyridine-induced epileptiform activity in young and adult rat hippocampus. Epilepsy Res 12: 207-215, 1992.

GIBBS JW III, SCHRODER GB, COULTER DA: GABA A receptor function in developing rat thalamic reticular neurons: whole cell recordings of GABA-mediated currents and modulation by clonazepam. $J$ Neurophysiol 76: 2568-2579, 1996.

HARTINGS JA, TEMEREANCA S, SIMONS DJ: State-dependent processing of sensory stimuli by thalamic reticular neurons. J Neurosci 23: 5264-5271, 2003.

HUGUENARD JR, PRINCE DA: A novel T-type current underlies prolonged $\mathrm{Ca}^{2+}$-dependent burst firing in GABAergic neurons of rat thalamic reticular nucleus. J Neurosci 12: 3804-3817, 1992.

JOHNSON SW, SEUTIN V: Bicuculline methiodide potentiates NMDA-dependent burst firing in rat dopamine neurons by blocking apamin-sensitive $\mathrm{Ca}^{2+}$-activated $\mathrm{K}^{+}$currents. Neurosci Lett 231: 13-16, 1997.

LIU XB, MURRAY KD, JONES EG: Switching of NMDA receptor 2A and 2B subunits at thalamic and cortical synapses during early postnatal development. J Neurosci 24: 8885-8895, 2004.

LLINÁS RR, STERIADE M: Bursting of thalamic neurons and states of vigilance. J Neurophysiol 95: 3297-3308, 2006. 
MAREŠ P, MAREŠOVÁ D, TROJAN S, FISCHER J: Ontogenetic development of rhythmic thalamo-cortical phenomena in the rat. Brain Res Bull 8: 765-769, 1982.

MOLINEUX ML, MCRORY JE, MCKAY BE, HAMID J, MEHAFFEY WH, REHAK R, SNUTCH TP, ZAMPONI GW, TURNER RW: Specific T-type calcium channel isoforms are associated with distinct burst phenotypes in deep cerebellar nuclear neurons. Proc Natl Acad Sci USA 103: 5555-5560, 2006.

MCCORMICK DA, TRENT F, RAMOA AS: Postnatal development of synchronized network oscillations in the ferret dorsal lateral geniculate and perigeniculate nuclei. J Neurosci 15: 5739-5752, 1995.

RAMOA AS, MCCORMICK DA: Developmental changes in electrophysiological properties of LGNd neurons during reorganization of retinogeniculate connections. J Neurosci 14: 2089-2097, 1994.

PEREZ-REYES E: Molecular physiology of low-voltage-activated t-type calcium channels. Physiol Rev 83: 117-161, 2003.

PIOTRKIEWICZ M, KUDINA L, MIERZEJEWSKA J, JAKUBIEC M, HAUSMANOWA-PETRUSEWICZ I: Agerelated change in duration of afterhyperpolarization of human motoneurones. $J$ Physiol Lond 585: 483-490, 2007.

SANCHEZ RM, JENSEN FE: Maturational aspects of epilepsy mechanisms and consequences for the immature brain. Epilepsia 42: 577-585, 2001.

SHIN HS: T-type $\mathrm{Ca}^{2+}$ channels and absence epilepsy. Cell Calcium 40: 191-196, 2006.

SHU Y, MCCORMICK DA: Inhibitory interactions between ferret thalamic reticular neurons. J Neurophysiol 87: 25712576, 2002.

SOHAL VS, HUGUENARD JR: Inhibitory interconnections control burst pattern and emergent network synchrony in reticular thalamus. J Neurosci 23: 8978-8988, 2003.

SOHAL VS, HUNTSMAN MM, HUGUENARD JR: Reciprocal inhibitory connections regulate the spatiotemporal properties of intrathalamic oscillations. J Neurosci 20: 1735-1745, 2000.

WARREN RA, JONES EG: Maturation of neuronal form and function in a mouse thalamo-cortical circuit. $J$ Neurosci 17: 277-295, 1997.

WELSBY PJ, WANG H, WOLFE JT, COLBRAN RJ, JOHNSON ML, BARRETT PQ: A mechanism for the direct regulation of T-type calcium channels by $\mathrm{Ca}^{2+} /$ calmodulin-dependent kinase II. $J$ Neurosci 23:10116-10121, 2003.

WOLFART J, ROEPER J: Selective coupling of T-type calcium channels to SK potassium channels prevents intrinsic bursting in dopaminergic midbrain neurons. $J$ Neurosci 22: 3404-3413, 2002.

WU WW, CHAN CS, DISTERHOFT JF: Slow afterhyperpolarization governs the development of NMDA receptordependent afterdepolarization in CA1 pyramidal neurons during synaptic stimulation. $J$ Neurophysiol 92: 2346-2356, 2004.

YING SW, GOLDSTEIN PA. Propofol-block of SK channels in reticular thalamic neurons enhances GABAergic inhibition in relay neurons. J Neurophysiol 93: 1935-1948, 2005.

ZHANG L, JONES EG: Corticothalamic inhibition in the thalamic reticular nucleus. $J$ Neurophysiol 91: 759-766, 2004.

ZHANG L, WARREN RA: Postnatal development of excitatory postsynaptic currents in nucleus accumbens medium spiny neurons. Neuroscience 154: 1440-1449, 2008. 